\title{
Characterization of boron-doped coal-derived carbon foams and their oxidation behaviour
}

\section{Elena Rodríguez, Roberto García*}

Instituto Nacional del Carbón (CSIC), Francisco Pintado Fe 26, 33011 Oviedo, Spain

\section{ABSTRACT}

Carbon foams with improved resistance to oxidation were obtained from a bituminous coal and different boron precursors (boron oxide, boron carbide, pyridine-borane complex), by controlled carbonisation under the pressure derived from the release of the volatile matter, which also acts as the foaming agent. The foams were subsequently carbonised at $1100{ }^{\circ} \mathrm{C}$ and the presence of boron gives rise to an increasing disorder in the carbon structure. After heat treatment at $2400{ }^{\circ} \mathrm{C}$, it is confirmed that boron occupies substitutional positions in the graphitic layers, and at high boron loadings ( $>$ $2.5 \%$ ), boron clusters, boron carbide and $\mathrm{BC}_{2} \mathrm{O}$ structures are also observed. The presence of boron has two opposite effects on the oxidation behaviour of the foams. At low B loadings, the foams obtained with boron carbide display lower oxidation temperatures. In the other foams, increases in the temperature of oxidation and the amount of residue remaining after the oxidation tests are observed. 


\section{Introduction}

Carbon foams are light weight materials, with a high mechanical strength, a low thermal expansion coefficient, and a high thermal and electrical conductivity that make them suitable for numerous thermal, mechanical and electrochemical applications [1-4]. In the manufacture of carbon foams, coals are an economical alternative [5] to other typical precursors such us polymers [6-9] or mesophase pitches $[5,10,11]$. The manufacture of coal-based carbon foams does not require any previous preparation of the precursor, foaming agents or stabilization steps, making for a simpler foaming process. The properties of the final carbon foams can be controlled by adjusting the foaming operating conditions (temperature and pressure), and the plastic behaviour of the precursor [12].

At the elevated temperatures typical of thermal isolation or heat exchange applications $\left(500-1200{ }^{\circ} \mathrm{C}\right)$, normally associated with oxidizing conditions, carbons readily chemisorb oxygen and subsequently desorb carbon oxides. This oxidation process results in the degradation of the original structure and properties of the material. Thus, carbon corrosion is a major problem that can impede the use of foams and other carbon materials at high temperatures.

Protection against the oxidation of carbon materials has been extensively studied using a wide variety of methods [13]. Various studies have revealed that the use of surface coatings prevents interaction between carbon and oxygen. For example, certain carbides and borides have shown promising results in protecting carbon materials (fibres, carbon-carbon composites, graphite and graphite foams) [14-16]. However, the thermal expansion of most coatings differs from that of carbon and, as a consequence, 
cracks in the coating can develop, as a result of which the carbon is exposed to high temperature oxygen atmospheres.

A promising method to overcome this drawback is based on the incorporation of certain heteroatoms into the carbon material. Boron, phosphorus, or halogens have been reported to provide intrinsic oxidation protection. Specifically, boron has the unique property of replacing carbon in the graphene layer, altering the electronic structure; this reduces the number of active sites and their reactivity [17]. Many studies have shown that boron-doping at high temperature can introduce boron atoms into substitutional positions in the carbon lattice $[18,19]$, thereby improving the oxidation resistance of graphite [18,20,21], carbon fibres [22-24], C/C composites [25-28], and other carbon materials [29-35]. Moreover, boron-doped carbons can also be prepared at low temperature by co-pyrolysing pitch with a suitable boron compound, e.g. pyridineborane complex [36].

Inhibition of carbon oxidation by substitutional boron may be a consequence of [22,24,29]: (1) blockage of specific surface active sites by boron oxide formed as the carbon conversion proceeds, (2) boron catalysing graphitization of the carbon, resulting in a more ordered and oxidation-resistant graphitic carbon, and (3) substitutional boron lowering the electron density on the reactive carbon atoms and, hence, having a suppression effect on $\mathrm{O}_{2}$ chemisorption. However, in certain cases a catalytic effect has been observed on the desorption of $\mathrm{CO}$ and $\mathrm{CO}_{2}$ due to the presence of substitutional boron, which lowers the Fermi level and redistributes the delocalized $\pi$-electrons in a way that strengthens the $\mathrm{C}-\mathrm{O}$ bonds but weakens the adjacent $\mathrm{C}-\mathrm{C}$ bonds.

This work is an attempt of manufacturing coal-derived carbon foams with enhanced oxidation resistance, for high temperature applications, by doping with boron. The behaviour of boron-doped carbon foams towards oxidation has been studied by 
thermogravimetric analysis (TGA). Different boron compounds and loadings were used to study their effect on the properties of the resultant foam.

Table 1

Analytical data of the Litwak coal used as precursor for carbon foams

Gieseler plasticity test

Softening temperature $\left({ }^{\circ} \mathrm{C}\right)$

Solidification temperature $\left({ }^{\circ} \mathrm{C}\right)$

498

Maximum fluidity temperature $\left({ }^{\circ} \mathrm{C}\right)$

Fluidity (ddpm)

80

Crucible swelling test

Swelling index

Proximate analysis

Volatile matter (\% d.b.)

Ash (\% d.b.)

ddpm: dial divisions per minute as obtained by the Gieseler

plasticity test (ASTM D2639-98).

d.b.: dry basis

\section{Materials and methods}

A low volatile bituminous coal (Litwak, from USA) was used as the precursor of the carbon foam. The characterisation data of the coal are summarized in Table 1. As boron source, three different boron compounds were used: boron oxide $\left(\mathrm{B}_{2} \mathrm{O}_{3}\right.$, Aldrich), 
boron carbide $\left(\mathrm{B}_{4} \mathrm{C}\right.$, Aldrich), and a borane-pyridine complex $\left(\mathrm{C}_{5} \mathrm{H}_{5} \mathrm{~N} \cdot \mathrm{BH}_{3}, 8 \mathrm{M}\right.$ in pyridine, Aldrich).

The carbon foam preparation technique used in this study is similar to that previously reported [12]. The key of the process is a pressurised carbonisation that was carried out in a conical trunk-shaped stainless steel reactor. In a typical experiment, the coal (20 g, ground to $<212 \mu \mathrm{m})$ was mixed with boron oxide or boron carbide, at initial loadings of $0.75,1.5,2.5$ and $5 \%$ of $\mathrm{B}$ mass, and the blend was homogenized for 20 minutes. It was then moulded and pressed, to produce a cylindrical piece. The latter was wrapped in aluminium foil and loaded into the reactor, which was subsequently pressurised with argon until the initial pressure (30 bar) was reached. The reactor was then heated in a fluidised sand bed oven with a heating rate of $2{ }^{\circ} \mathrm{C} \min ^{-1}$ up to $475{ }^{\circ} \mathrm{C}$, and a soaking time of $2 \mathrm{~h}$. Under these conditions, the volatile matter released from the softened coal acts as the foaming agent, while the pressure, which final value increases with the initial proportion of the boron compound in the blend (from 70 bar in the absence of boron compound to 120 bar with a $5 \%$ of the latter) determines the pore structural characteristics of the resultant foam.

In the next step, the green foam obtained in this manner was heated under argon at a rate of $1{ }^{\circ} \mathrm{C} \min ^{-1}$ up to $1100{ }^{\circ} \mathrm{C}$ with a soaking time of $1 \mathrm{~h}$. To incorporate the boron substitutionally into the carbon foam, a high temperature treatment was carried out under argon at $2400{ }^{\circ} \mathrm{C}$, using a Pirox VI 150/25 graphite furnace.

As the organoborane complex decomposes at about $120^{\circ} \mathrm{C}$ into pyridine and highly reactive borane, the preparation of the foams using this precursor followed a different procedure. The coal $(2 \mathrm{~g}$, ground to $<212 \mu \mathrm{m})$ was placed in a cylindrical steel reactor ( $1.4 \mathrm{~cm}$ internal diameter $\mathrm{x} 11.5 \mathrm{~cm}$ height) and then the pyridine solution of the organoborane complex was added dropwise, at initial loadings of 1.95, 4.5 and $9 \%$ of B 
mass, under Ar atmosphere. Taking advantage of the maximum fluidity of the coal (which occurs at $473{ }^{\circ} \mathrm{C}$, Table 1) to improve the reaction with borane, the first foaming step was carried out at $475{ }^{\circ} \mathrm{C}$ with a soaking time of $2 \mathrm{~h}$. The reactor was closed at atmospheric pressure and then placed inside a cylindrical furnace, previously heated to the required reaction temperature. Subsequent treatments at $1100{ }^{\circ} \mathrm{C}$ and $2400{ }^{\circ} \mathrm{C}$ were carried out in a way similar to those used for the boron oxide and boron carbide foams.

The codes used to designate the samples indicate: the percentage of B loaded (from 0.75 to $9 \%$ ), the boron precursor (boron oxide: BO; boron carbide: BC; pyridineborane complex: $\mathrm{PB}$ ), and the heat treatment temperature (11 stands for $1100{ }^{\circ} \mathrm{C}$ and 24 for $2400{ }^{\circ} \mathrm{C}$ ). For example, $0.7 \mathrm{BO} 24$ is the foam doped with $0.75 \% \mathrm{~B}$, using boron oxide as precursor, and subsequently heat treated at $2400{ }^{\circ} \mathrm{C}$. Appropriate boron-free carbon foams, obtained by the two preparation procedures described, were used as reference materials: $0.0 \mathrm{~B} 11$ and $0.0 \mathrm{~B} 24$, obtained by means of the $\mathrm{B}_{2} \mathrm{O}_{3}$ and $\mathrm{B}_{4} \mathrm{C}$ procedure, and $0.0 \mathrm{~PB} 11$ and $0.0 \mathrm{~PB} 24$, by means of the pyridine-borane complex one.

Table 2

Textural properties of two of the carbon foams

\begin{tabular}{lcc}
\hline Foam & $0.0 \mathrm{~B} 24$ & $5.0 \mathrm{BC} 24$ \\
True density $\left(\rho_{\mathrm{He}}, \mathrm{g} \mathrm{cm}^{-3}\right)$ & 1.95 & 2.00 \\
Apparent density $\left(\rho_{\mathrm{Hg}}, \mathrm{g} \mathrm{cm}^{-3}\right)$ & 0.47 & 0.57 \\
Open porosity $(\varepsilon, \%)$ & 75.95 & 71.40 \\
Total pore volume $\left(\mathrm{V}_{\mathrm{T}}, \mathrm{g} \mathrm{cm}^{-3}\right)$ & 1.62 & 1.25 \\
\hline
\end{tabular}

As an example, Table 2 lists the textural properties of two of the foams obtained in this study, with and without boron-doping. In terms of pore distribution, Fig. 1 
displays the differential pore volume of these foams. The size of the majority of the pores in the undoped foam is $\approx 20 \mu \mathrm{m}$. Pore sizes in the B-doped foam are smaller and less homogenous.

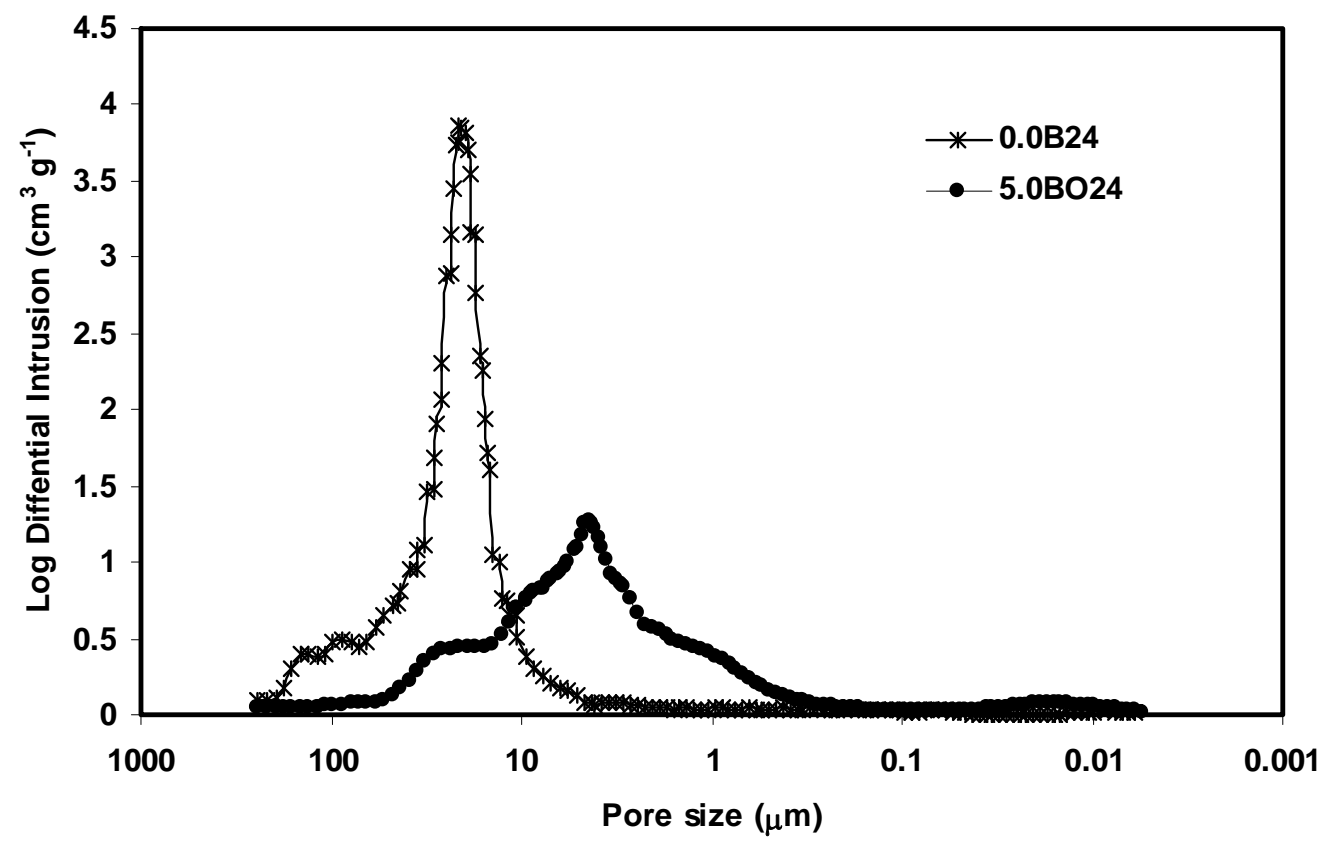

Fig. 1. Differential pore volume of two of the foams studied.

Boron loadings in the graphitic carbon foams were determined by inductively coupled plasma (ICP) emission spectroscopy, using an Agilent 7500ce instrument. The samples were digested by fusing them with sodium peroxide, the resulting melt being dissolved in water together with a small amount of hydrochloric acid. The solution was then analyzed by the method of standard additions.

X-ray diffractometry (XRD) was employed to measure crystallinity changes. Scans were made between 18 and $90^{\circ}(2 \theta)$ using a step size of $0.02^{\circ} \mathrm{s}^{-1}$ and a step time of $2 \mathrm{~s}$, by means of a parallel-beam X-ray diffraction system (Bruker, model D8 Advance power diffractometer), equipped with a göbel mirror in the incident beam and 
a parallel-slits analyzer in the diffracted beam. The interlayer spacing, $\mathrm{d}_{002}$, was evaluated from the position of the (002) peak by applying the Bragg equation. The crystallite sizes, $\mathrm{L}_{c}$ and $\mathrm{L}_{\mathrm{a}}$, were calculated from the (002) and (110) peaks, respectively, using the Scherrer formula, with $K$ values of 0.9 for $L_{c}$ and 1.84 for $L_{a}$.

X-ray photoelectron spectroscopy (XPS) was carried out by means of a Specs spectrometer equipped with a high performance Phoibos 100 hemispherical analyser and a 5 multiplier channeltron detector $(5 \mathrm{MCD})$. The X-ray radiation was a non monochromatic $\mathrm{MgK} \alpha(1253.6 \mathrm{eV})$ emitted from a double anode at $50 \mathrm{w}$.

The Raman spectra were recorded on a Raman microspectrometer (HR-800 Jobin Yvon Horiba). The source of radiation was a laser operating at a wavelength of $532 \mathrm{~nm}$ and a power of $25 \mathrm{~mW}$. Extended scans from 1700 to $1225 \mathrm{~cm}^{-1}$ were performed to obtain the first-order Raman spectra of the samples, with typical exposure times of $30 \mathrm{~s}$. To assess differences within the samples, at least 21 measurements were performed on different particles of each individual sample. The intensity of the Raman bands was measured using a mixed Gaussian-Lorentzian curve-fitting procedure.

The oxidation behaviour was analyzed in a thermogravimetric analyzer (TA Instruments, mod. STD 2960). The measurements were carried out in dry air at 1 atm

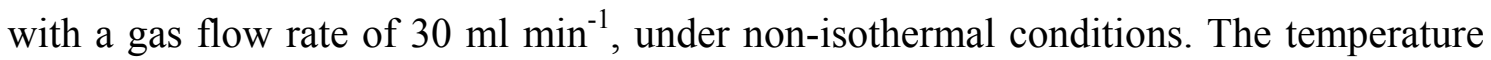
was raised to $1200{ }^{\circ} \mathrm{C}$ at a heating rate of $10{ }^{\circ} \mathrm{C} \mathrm{min}^{-1}$. In all the analyses, samples were cut into cylindrical pieces $(\sim 10 \mathrm{mg})$, which were then placed in platinum crucibles. Mass changes were monitored with a microbalance. 


\section{Results}

\subsection{Boron retention analysis}

The final B concentration in the graphitised samples and the efficiencies of B doping or loading are summarized in Table 3. When any of the inorganic precursors were used, the maximum theoretical boron doping was $\approx 5 \%$. For higher loadings, it was impossible to obtain suitable green foams. However, when the pyridine-borane precursor was used, higher B loadings, up to $9 \%$, were possible. Doping efficiency seems to depend on both the type of doping compound and its concentration. Thus, for the inorganic precursors, doping efficiency increases from 20 to $60 \%$ as the theoretical B doping increases from $0.75 \%$ to $1.5 \%$. However, for the organoborane complex, it is necessary to use more than $5 \%$ to achieve high efficiencies. Below that, only $29 \%$ of boron retention could be obtained with the complex, which is well below the 56 and $44 \%$ reached with boron carbide and boron oxide, at similar B loadings.

The discrepancy between theoretical and experimental loadings is thought to be due to the migration of $\mathrm{B}$ to the reactor during the heat treatments. In the case of the organoborane complex the loss of $\mathrm{B}$ is higher, due to its lower vapour pressure compared to that of the inorganic precursors. These results are fairly similar to those of other carbon materials and boron precursors which can be found in the literature [37]. 
Table 3

Boron content in different graphitic foams and their B doping efficiency

\begin{tabular}{|c|c|c|c|}
\hline Sample & $\mathrm{B}_{\exp }($ wt. $\%)$ & $\mathrm{B}_{\text {theor }}(\mathrm{wt} . \%)$ & $\mathrm{B}_{\mathrm{eff}}(\%)$ \\
\hline $0.0 \mathrm{~B} 24$ & $<0.05$ & - & - \\
\hline $0.7 \mathrm{BO} 24$ & 0.14 & 0.75 & 19 \\
\hline $1.5 \mathrm{BO} 24$ & 0.88 & 1.50 & 59 \\
\hline $2.5 \mathrm{BO} 24$ & 1.50 & 2.50 & 60 \\
\hline $5.0 \mathrm{BO} 24$ & 2.20 & 5.00 & 44 \\
\hline $0.7 \mathrm{BC} 24$ & 0.18 & 0.75 & 24 \\
\hline $1.5 \mathrm{BC} 24$ & 0.92 & 1.50 & 61 \\
\hline $2.5 \mathrm{BC} 24$ & 1.61 & 2.50 & 64 \\
\hline $5.0 \mathrm{BC} 24$ & 2.80 & 5.00 & 56 \\
\hline $0.0 \mathrm{~PB} 24$ & $<0.05$ & - & - \\
\hline 1.9PB24 & 0.43 & 1.95 & 22 \\
\hline 4.5PB24 & 1.30 & 4.50 & 29 \\
\hline 9.0PB24 & 5.63 & 9.00 & 62 \\
\hline \multicolumn{4}{|c|}{$\mathrm{B}_{\text {exp }}$ : determined by ICP-MS } \\
\hline \multicolumn{4}{|c|}{$\mathrm{B}_{\text {theor: }}$ initially added B } \\
\hline$B_{\text {eff: }}: B$ & acy & & \\
\hline
\end{tabular}

\subsection{Characterization of boron-doped foams}

The interplanar spacing results $\left(\mathrm{d}_{002}\right)$, derived from XRD analyses of the undoped carbonised foam $0.0 \mathrm{~B} 11$ is $0.3516 \mathrm{~nm}$. This value increases with the increasing 
B loading in the foams obtained with boron oxide and boron carbide, up to 0.3536 (5.0BO11) and $0.3539 \mathrm{~nm}(5.0 \mathrm{BC} 11)$, respectively. This indicates an increase in the disorder when the B load is increased and suggests that the substitution process that incorporates the $\mathrm{B}$ into the carbonaceous structure has not occurred yet at the carbonisation temperature $\left(1100{ }^{\circ} \mathrm{C}\right)$. Thus, the initial precursor and its bonds persist, generating defects in the structure (Fig. 2).

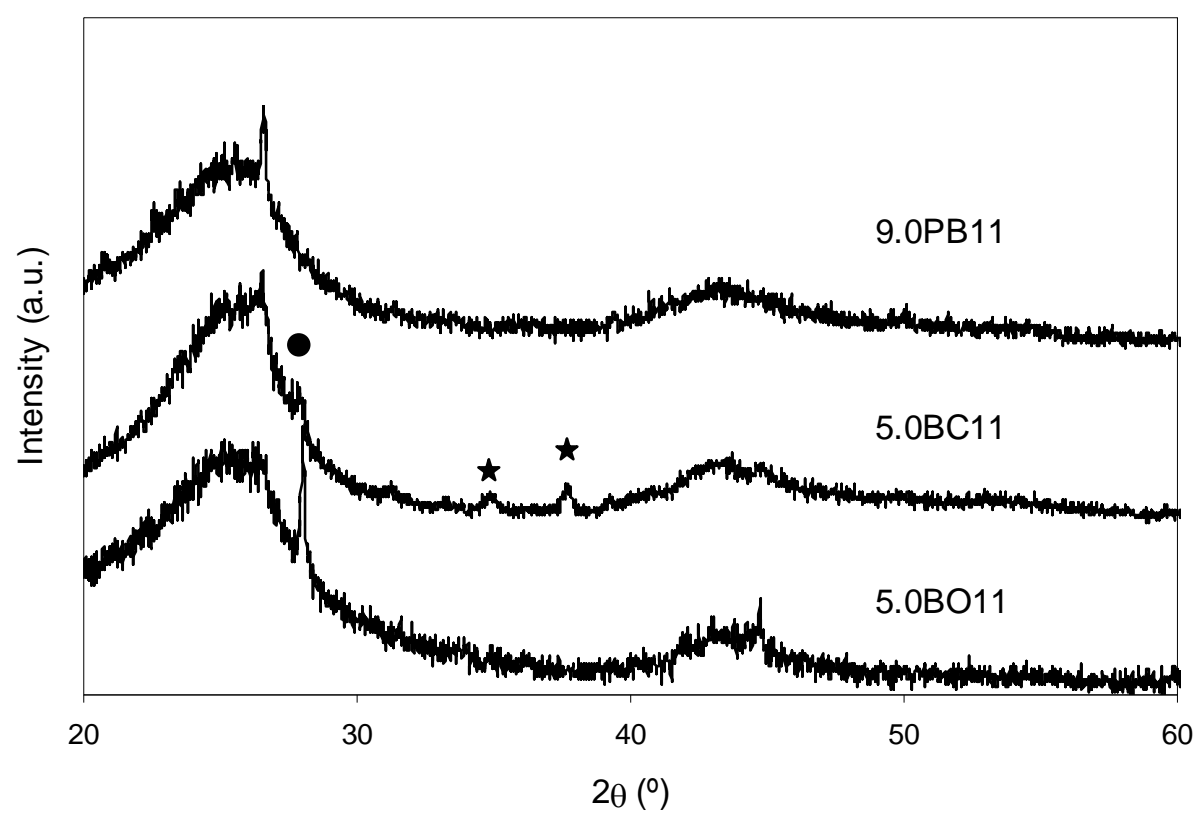

Fig. 2. XRD spectra of doped-foams synthesized at $1100{ }^{\circ} \mathrm{C}$ with different boron precursors. (•) $\mathrm{B}_{2} \mathrm{O}_{3}$ bands; ( $\star$ ) $\mathrm{B}_{4} \mathrm{C}$ bands.

In the case of the pyridine-borane complex, an increase in $\mathrm{d}_{002}$ is observed, from 0.3485 in $0.0 \mathrm{~PB} 11$ to 0.3531 in $9.0 \mathrm{~PB} 11$. Boron oxide and boron carbide are not seen in the difractograms (Fig. 2). In this case, the increase in $\mathrm{d}_{002}$ must be attributed either to the loss of planarity in the graphene layers as a consequence of the replacement of the carbon atoms by boron, or to the presence of B atoms in interstitial positions [38]. 
Table 4

XRD parameters of the graphitic carbon foams

\begin{tabular}{lccc}
\hline Samples & $\mathrm{d}_{002}(\mathrm{~nm})$ & $\mathrm{L}_{\mathrm{c}}(\mathrm{nm})$ & $\mathrm{L}_{\mathrm{a}}(\mathrm{nm})$ \\
\hline $0.0 \mathrm{~B} 24$ & 0.3386 & 19.8 & 53.1 \\
\hline $0.7 \mathrm{BO} 24$ & 0.3383 & 18.5 & 53.7 \\
$1.5 \mathrm{BO} 24$ & 0.3379 & 20.3 & 57.8 \\
$2.5 \mathrm{BO} 24$ & 0.3372 & 24.4 & 57.2 \\
$5.0 \mathrm{BO} 24$ & 0.3370 & 26.8 & 63.6 \\
\hline $0.7 \mathrm{BC} 24$ & 0.3375 & 24.0 & 57.6 \\
$1.5 \mathrm{BC} 24$ & 0.3370 & 26.6 & 54.6 \\
$2.5 \mathrm{BC} 24$ & 0.3368 & 29.9 & 58.4 \\
$5.0 \mathrm{BC} 24$ & 0.3363 & 39.7 & 62.5 \\
\hline $0.0 \mathrm{~PB} 24$ & 0.3385 & 22.2 & 51.6 \\
\hline 1.9PB24 & 0.3376 & 26.8 & 58.7 \\
4.5PB24 & 0.3371 & 25.2 & 54.9 \\
\hline .0 PB24 & 0.3361 & 41.5 & 63.8 \\
\hline
\end{tabular}

Increasing the heat treatment temperature up to $2400{ }^{\circ} \mathrm{C}$ enhances the structural ordering in the doped foams due to the B catalytic effect on graphitisation. This can be inferred from the structural parameters obtained from the XRD analysis (interlayer or interplanar spacing, $\mathrm{d}_{002}$, average crystallite height, $\mathrm{L}_{\mathrm{c}}$, and crystallite diameter, $\mathrm{L}_{\mathrm{a}}$ ) of the foams treated at $2400{ }^{\circ} \mathrm{C}$, listed in Table 4 . The doped samples show large crystallite sizes and small interlayer distances, approaching that of the natural graphite $(0.3354$ $\mathrm{nm})$ [23]. In addition, the intensity of the (101), (004) and (112) peaks increases with 
the amount of boron added, and the separation between peaks (100) and (101) becomes clearer, as shown in Fig. 3. These results indicate that boron doping improves the crystallinity of carbon foams, which supports the view that boron is substitutionally positioned in the hexagonal graphitic layers. The enhancement of graphitization by substitutional boron has been extensively studied $[23,39]$.
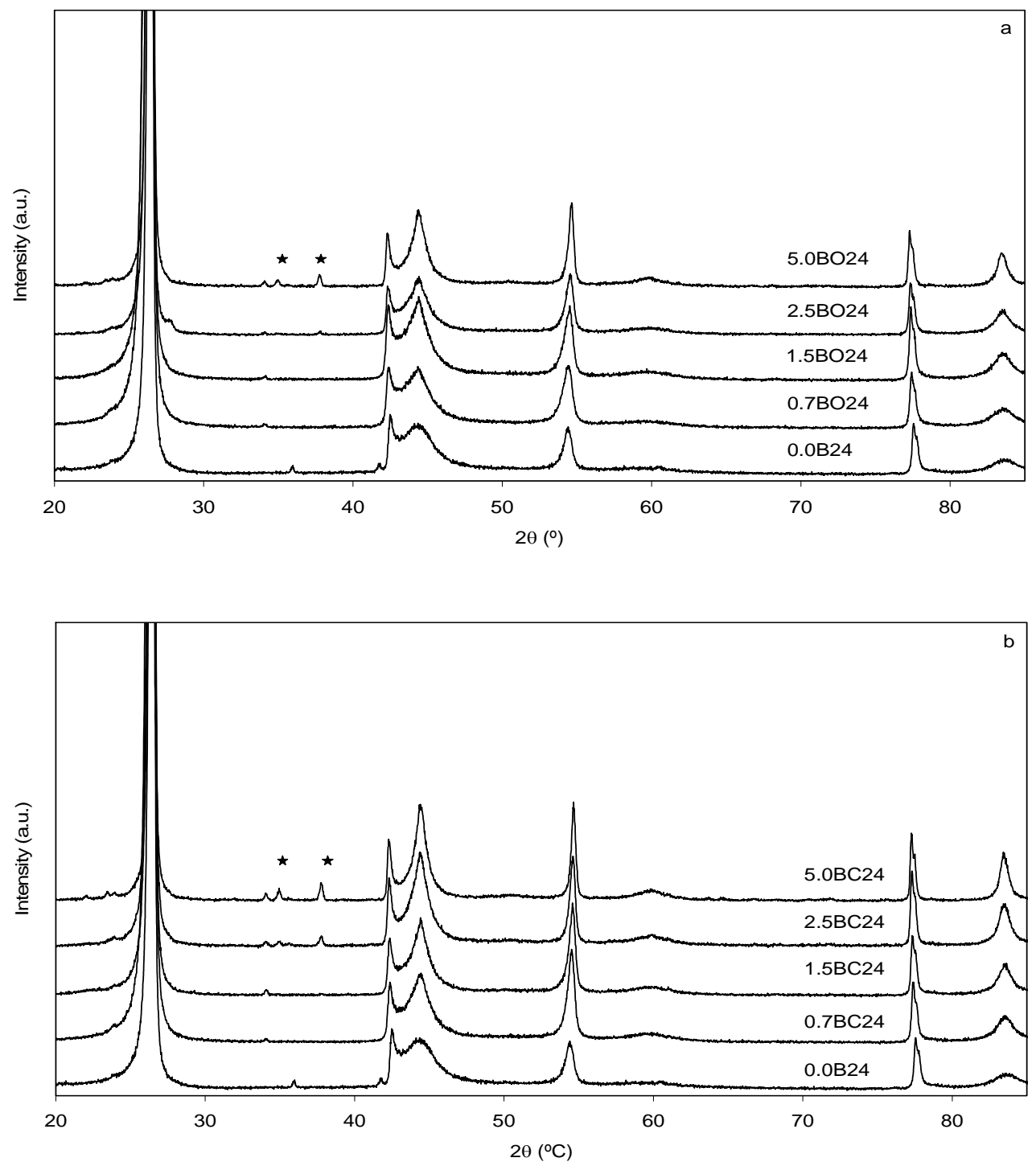

Fig. 3. XRD spectra of graphitic foams doped with: a) boron oxide; b) boron carbide; c) pyridine-borane complex. ( $\star$ ) $\mathrm{B}_{4} \mathrm{C}$. 


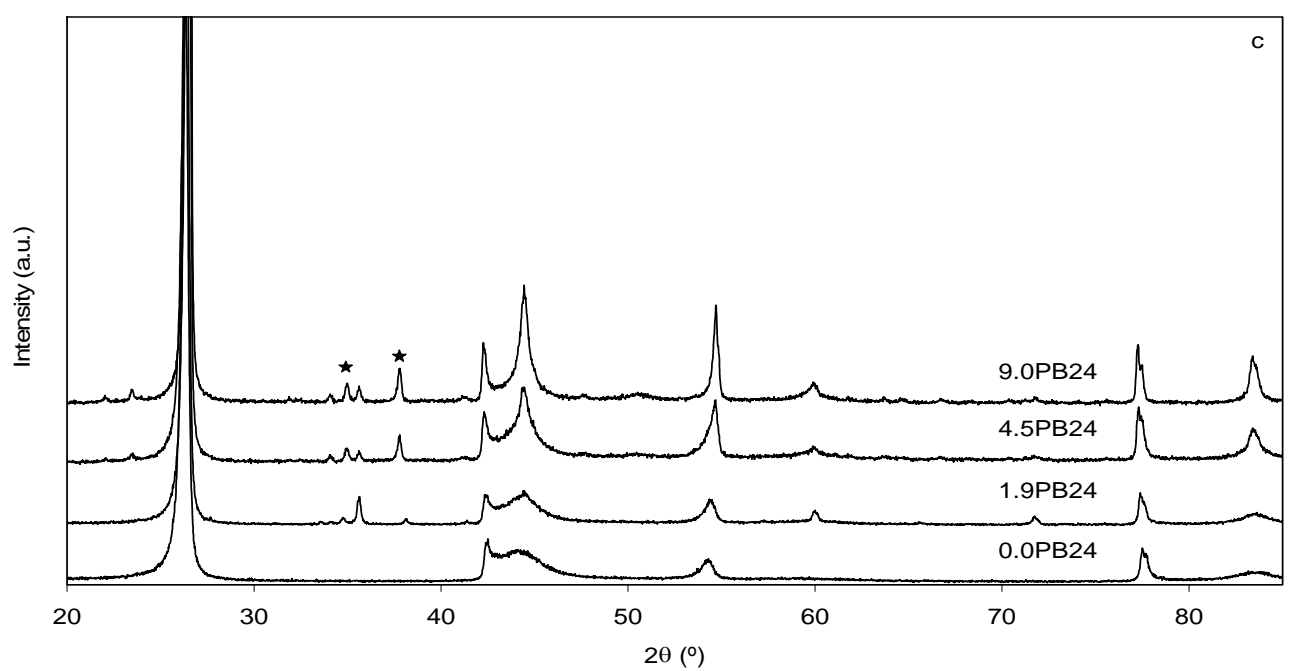

Fig. 3 (cont.). XRD spectra of graphitic foams doped with: a) boron oxide; b) boron carbide; c) pyridine-borane complex. ( $\star) \mathrm{B}_{4} \mathrm{C}$.

When the amount of the boron loaded is increased above $2.5 \%$, peaks corresponding to $\mathrm{B}_{4} \mathrm{C}$ appeared, even for the samples prepared with boron oxide and the pyridine-borane complex. Therefore, this compound must have been formed during the graphitization process. This is because the maximum capacity of the boron to dissolve into graphite foams has been reached, forcing the excess boron to migrate to other phases.

XPS measurements of the boron-doped foams were carried out to determine whether the replacement of carbon atoms by boron atoms had taken place. The $\mathrm{B}_{1 \mathrm{~s}}$ peak is not present either in the undoped carbon foams, 0.0B11, 0.0B24, 0.0PB11 and 0.0PB24, or in the foams doped with the lowest B loadings: $0.75 \%$ for boron oxide and boron carbide (0.7BO24 and 0.7BC24), and 1.95\% for the complex (1.9PB24).

The carbonized foams $2.5 \mathrm{BO} 11$ and $2.5 \mathrm{BC} 11$, exhibit considerable amounts of boron and oxygen, which decrease drastically with the heat treatment at $2400{ }^{\circ} \mathrm{C}$ (Table 5). At $1100{ }^{\circ} \mathrm{C}$ boron is not present inside the carbon lattice (B-C), but in the oxidised 
form $\left(\mathrm{B}_{2} \mathrm{O}_{3}\right)$, with a peak at around $193.5 \mathrm{eV}$. In the case of $\mathrm{B}_{4} \mathrm{C}$ precursor, this means that interactions with the oxygenated functional groups present in the coal have taken place, at least in the coal surface. When the temperature is increased, the $\mathrm{B}_{1 \mathrm{~s}}$ band shifts towards lower energies (Fig. 4).

\section{Table 5}

Surface composition of carbonized and graphitised foams, determined by XPS (in atomic \%)

\begin{tabular}{cccccc}
\hline Samples & $\mathrm{C}$ & $\mathrm{O}$ & $\mathrm{B}$ & $\mathrm{N}$ & Others \\
\hline $2.5 \mathrm{~B} 011$ & 45.52 & 33.98 & 14.48 & 0.33 & 5.69 \\
$2.5 \mathrm{~B} 024$ & 96.98 & 2.10 & 0.92 & - & - \\
& & & & & \\
\hline $2.5 \mathrm{BC} 11$ & 56.39 & 24.41 & 12.48 & 0.31 & 6.41 \\
$2.5 \mathrm{BC} 24$ & 96.37 & 2.52 & 1.01 & - & - \\
\hline $4.5 \mathrm{~PB} 11$ & 80.43 & 11.38 & 2.76 & 2.83 & 2.60 \\
$4.5 \mathrm{~PB} 24$ & 94.64 & 3.03 & 1.10 & 1.27 & - \\
\hline
\end{tabular}
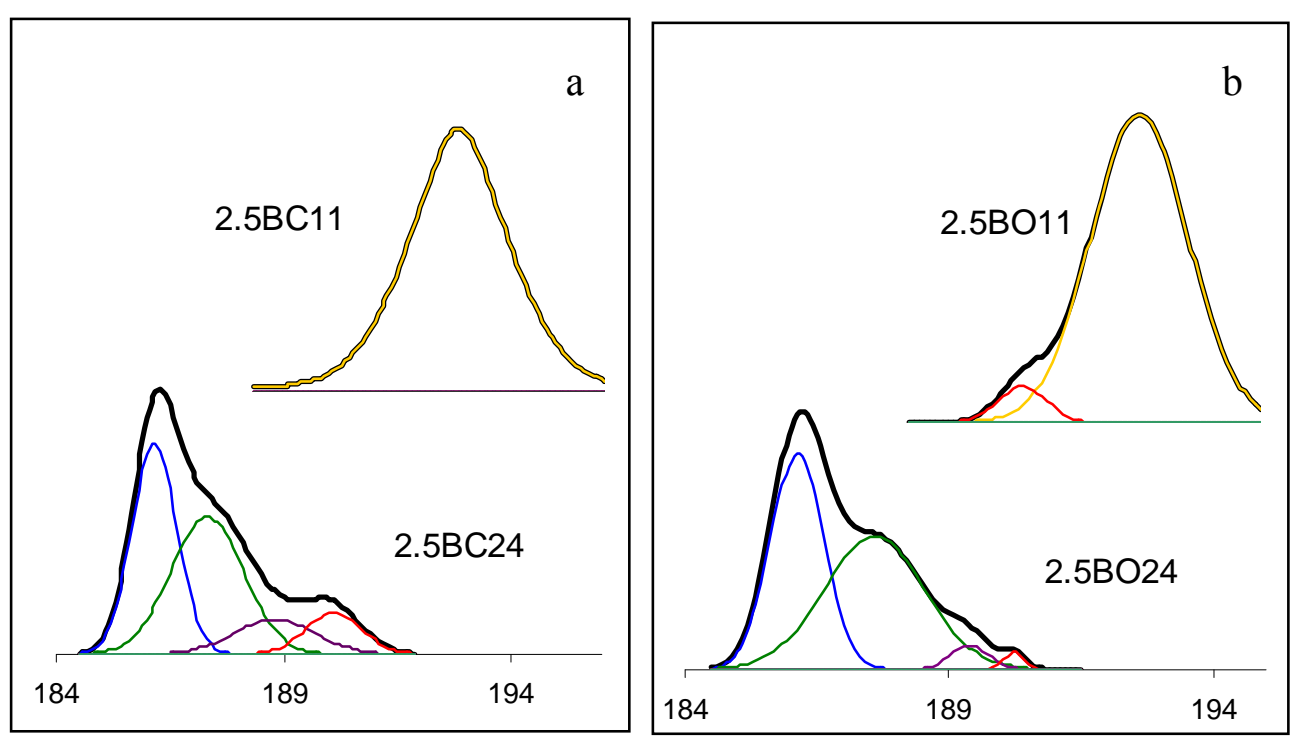

Fig. 4. XPS $B_{1 s}$ spectra of foams doped with: (a) boron oxide; (b) boron carbide. 
Four $\mathrm{B}_{1 \mathrm{~s}}$ peaks are identified in the high resolution $\mathrm{B}_{1 \mathrm{~s}}$ spectra of $2.5 \mathrm{BO} 24$ and 2.5BC24, as shown in Fig. 4. The binding energies corresponding to these peaks are $186.2,187.5,188.8$ and $190.2 \mathrm{eV}$, which are close to those reported for boron clusters, boron carbide $\left(\mathrm{B}_{4} \mathrm{C}\right)$, substitutional $\mathrm{B}(\mathrm{B}-\mathrm{C})$, and $\mathrm{B}-\mathrm{C}$ bonding in a partially oxidised trigonal geometry $\left(\mathrm{BC}_{2} \mathrm{O}\right)$ as a consequence of interstitial boron oxidation [27,30,34].

Table 6 gives the relative proportions of the boron forms in the doped foams. It can be seen that the intensity of the $\mathrm{B}_{1 \mathrm{~s}}$ peaks located at $187-189 \mathrm{eV}$ increases with the amount of boron added, in agreement with XRD observations (higher crystallinity and $\mathrm{B}_{4} \mathrm{C}$ content).

Table 6

Distribution ( $\%$ of total surface atoms) of the different boron forms, in the foams doped with $\mathrm{B}_{2} \mathrm{O}_{3}$ and $\mathrm{B}_{4} \mathrm{C}$ (deduced by XPS)

\begin{tabular}{lccccc}
\hline & & \multicolumn{4}{c}{ Boron type (Peak position, eV) } \\
\cline { 3 - 6 } & & Clusters & $\mathrm{B}_{4} \mathrm{C}$ & $\mathrm{B}-\mathrm{C}$ & $\mathrm{BC}_{2} \mathrm{O}$ \\
Samples & Total Boron & $(186.2)$ & $(187.5)$ & $(188.8)$ & $(190.2)$ \\
\hline $1.5 \mathrm{BO} 24$ & 0.62 & 0.48 & 0.09 & 0.05 & - \\
$2.5 \mathrm{BO} 24$ & 1.10 & 0.48 & 0.46 & 0.15 & 0.01 \\
$5.0 \mathrm{BO} 24$ & 1.24 & 0.46 & 0.58 & 0.19 & 0.02 \\
\hline $1.5 \mathrm{BC} 24$ & 0.88 & 0.56 & 0.25 & 0.06 & - \\
$2.5 \mathrm{BC} 24$ & 1.16 & 0.44 & 0.47 & 0.13 & 0.11 \\
$5.0 \mathrm{BC} 24$ & 1.22 & 0.35 & 0.56 & 0.30 & 0.01 \\
\hline
\end{tabular}


To a great extent, boron is present in the doped foams in the form of boron clusters, in contrast to previous studies in other carbon materials, like graphite, pitch, semicoke, etc., where B tends to move to substitutional positions and incorporate to the carbonaceous structure until its maximum solubility in graphite is reached, after which it begins to form boron carbide.

This different behaviour could be attributed to the large empty volume available in the macroporosity of the foams, so that the boron compound is able to accumulate within the pores, instead of being retained in the carbon structure. In this situation, the B is more likely to form clusters that will react with carbon. At higher B loadings, the transfer of the B to other phases begins and, then, the substitutional B (B-C) increases in conjunction with carbide.

The decrease in boron content between samples 4.5PB11 and 4.5PB24 is low compared with the $2.5 \mathrm{BO} 11 / 2.5 \mathrm{BO} 24$ or $2.5 \mathrm{BC} 11 / 2.5 \mathrm{BC} 24$ pairs (Table 5). This is due to the replacement of carbon atoms by boron taking place at $1100{ }^{\circ} \mathrm{C}$ when the pyridineborane complex is employed. At this temperature, the excess of B precursor is removed, resulting in low B loadings. The most remarkable effect of the increase in temperature, in this sample, is the loss of oxygen.

Fig. 5 corresponds to the XPS study of 4.5PB24 and 9.0PB24. In addition to carbon, boron and oxygen, measurable amounts of nitrogen are detected, as expected, due to the fact that doping with the pyridine-borane complex typically leads to the parallel incorporation of boron and nitrogen with the preferential formation of B-N bonds [40]. 


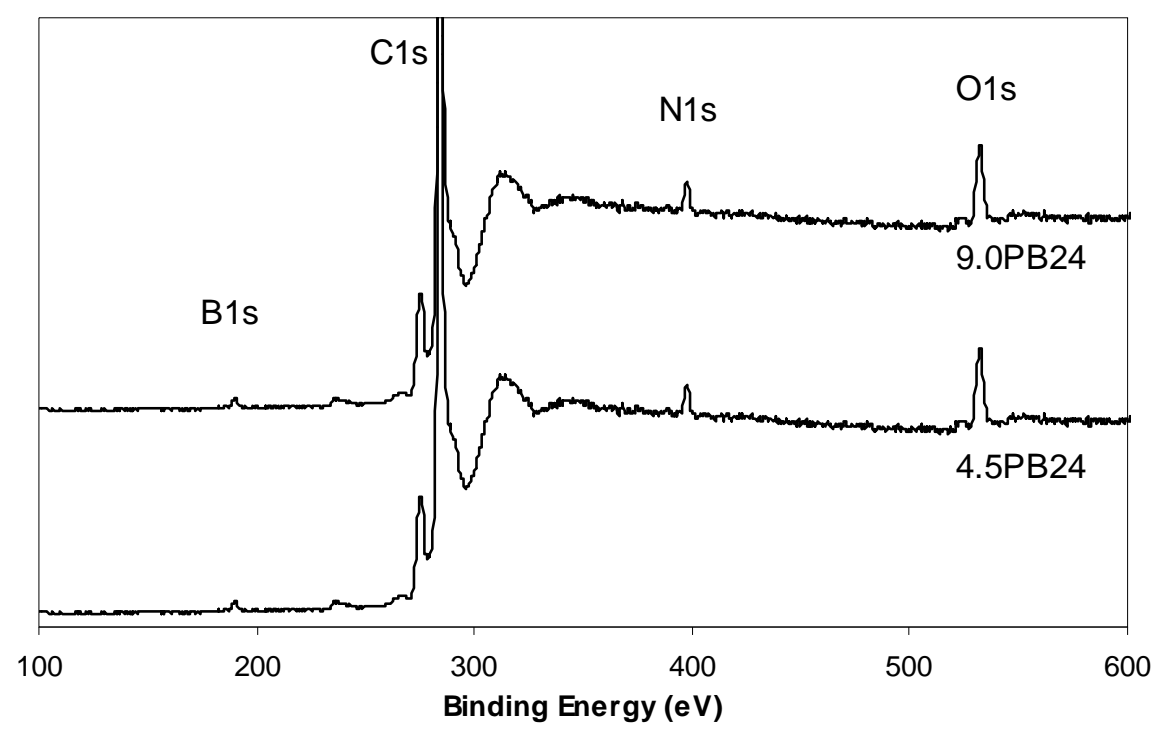

Fig. 5. XPS spectra of foams doped with the pyridine-borane complex.

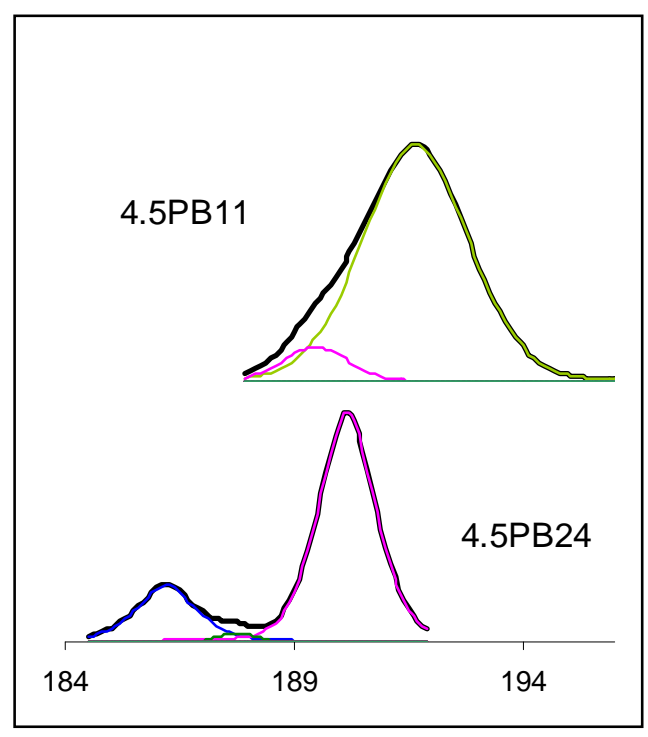

Fig. 6. XPS $\mathrm{B}_{1 \mathrm{~s}}$ spectra of foam 4.5PB11 at different heat treatments.

The deconvolution of the $\mathrm{B}_{1 \mathrm{~s}}$ band in the foam 4.5PB11 gives rise to two peaks at 190.1 and $192.3 \mathrm{eV}$ (Fig. 6). The first one can be attributed to boron bound to the incorporated nitrogen atoms (B-N), and the second to the presence of the oxidized form of the boron-nitrogen group $([\mathrm{O}]-\mathrm{B}-\mathrm{N})[38]$. The latter is the main feature in the spectra of the carbonized foams and can be attributed to the high amount of oxygen they 
contain. When the temperature is raised to $2400{ }^{\circ} \mathrm{C}$, this peak completely disappears and B-N gives rise to the largest peak in the spectrum (Fig. 6). Moreover, boron carbide and boron clusters appear in the graphitised foams (Fig. 6). The amount of boron carbide increases with increasing additions of boron (Table 7).

\section{Table 7}

Distribution ( $\%$ of total surface atoms), of the different boron forms in the boron-doped foams (deduced by XPS)

Boron type (Peak position, eV)

\begin{tabular}{lccccc}
\cline { 3 - 5 } Samples & Clusters & $\mathrm{B}_{4} \mathrm{C}$ & $\mathrm{B}-\mathrm{N}$ & $\mathrm{BCO}_{2}$ \\
& Total Boron & $(186.2)$ & $(187.5)$ & $(190.1)$ & $(192.3)$ \\
\hline 4.5PB24 & 1.10 & 0.19 & 0.02 & 0.89 & - \\
9.0 PB24 & 2.05 & 0.11 & 0.17 & 1.77 & - \\
\hline
\end{tabular}

Fig. 7 shows the shift of the $\mathrm{C}_{1 \mathrm{~s}}$ band in the boron-doped foams towards lower energies. This is caused by the presence of boron in the carbon structure which, due to its electron deficient character, lowers the Fermi level energy [23,24].

The high resolution $\mathrm{C}_{1 \mathrm{~s}}$ spectrum of $0.0 \mathrm{~B} 24$ shows a main peak at $284.4 \mathrm{eV}$, usually assigned to $\mathrm{C}$ in graphitic structures, and a shoulder at higher energies that corresponds to $\mathrm{C}$ in higher oxidation states. In the doped samples, the $\mathrm{C}_{1 \mathrm{~s}}$ peak moves to $283.8 \mathrm{eV}$, which Shirasaki et al. [41] assigned to carbon atoms in plane without boron atoms as first neighbours. If the boron loading were higher, a new band would appear at a lower energy, $282.6 \mathrm{eV}$, which is typically attributed to B-C bonding.

To further study the graphitic structure of the foams, some of the samples were analysed by Raman spectroscopy. Fig. 8 shows the spectra obtained from particles of 
samples $0.0 \mathrm{~B} 24,1.5 \mathrm{BO} 24,5.0 \mathrm{BO} 24$ and $4.5 \mathrm{~PB} 24$. These are characteristic of wellordered carbon materials, with three bands detected in the first-order region: a prominent G-band (after graphite) at $\sim 1580 \mathrm{~cm}^{-1}$, a less intense D-band (after defects) at $\sim 1350 \mathrm{~cm}^{-1}$, and the $\mathrm{D}^{\prime}$-band, appearing at $\sim 1620 \mathrm{~cm}^{-1}$ as a shoulder of the main graphite band.

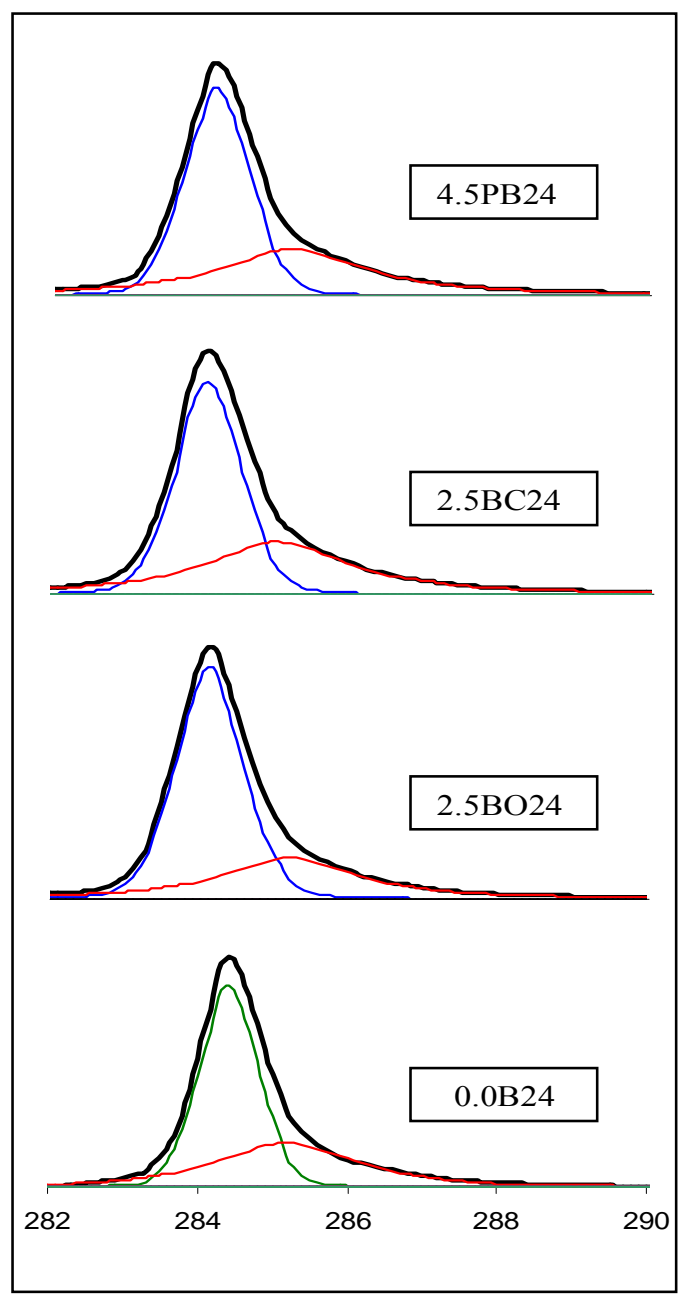

Fig. 7. XPS $\mathrm{C}_{1 \mathrm{~S}}$ spectra of undoped and doped foams. 




Fig. 8. Raman spectra of carbon foams.

The relative intensity of the Raman D-band, $\mathrm{I}_{\mathrm{D}} / \mathrm{I}_{t}\left(\mathrm{I}_{t}=\mathrm{I}_{\mathrm{G}}+\mathrm{I}_{\mathrm{D}}+\mathrm{I}_{\mathrm{D}^{\prime}}\right.$, where $\mathrm{I}_{\mathrm{G}}, \mathrm{I}_{\mathrm{D}}$ and $\mathrm{I}_{\mathrm{D}^{\prime}}$ are the intensities of G-, D- and D'-bands, respectively), is used as an indicator of the bidimensional disorder of carbon materials, and is also associated with the degrading of the crystalline orientation of the materials. Fig. 9 displays an increase in this ratio with the increasing boron content of the foam. These results seem to contradict those obtained by $\mathrm{XRD}$, because according to the relationship between $\mathrm{I}_{\mathrm{D}} / \mathrm{I}_{\mathrm{G}}$ and the inverse of $L_{a}$, postulated by Tuinstra and Koenig [42], they suggest that the doped foams ought to have crystal sizes smaller than the undoped foam. However, Cuesta et al. [43] have shown that several factors may affect the intensity and width of the D-band, apart from the finite size of the crystals: namely the degree of crystalline orientation or the presence of disordered carbon and interstitial or $\mathrm{sp}^{3}$ carbons. Hence, the formula by Tuinstra and Koenig is valid only as a first approximation to $L_{a}$ values, and errors as high as $100 \%$ are possible. The use of this formula is more appropriate for disordered 
carbons where direct $\mathrm{L}_{\mathrm{a}}$ measurement by $\mathrm{XRD}$ is complicated due to the poor definition of the (10) band. It should also be noted that these two techniques do not show the same sensitivity in detecting distortions. That is to say, they provide complementary information, rather than equivalent information.

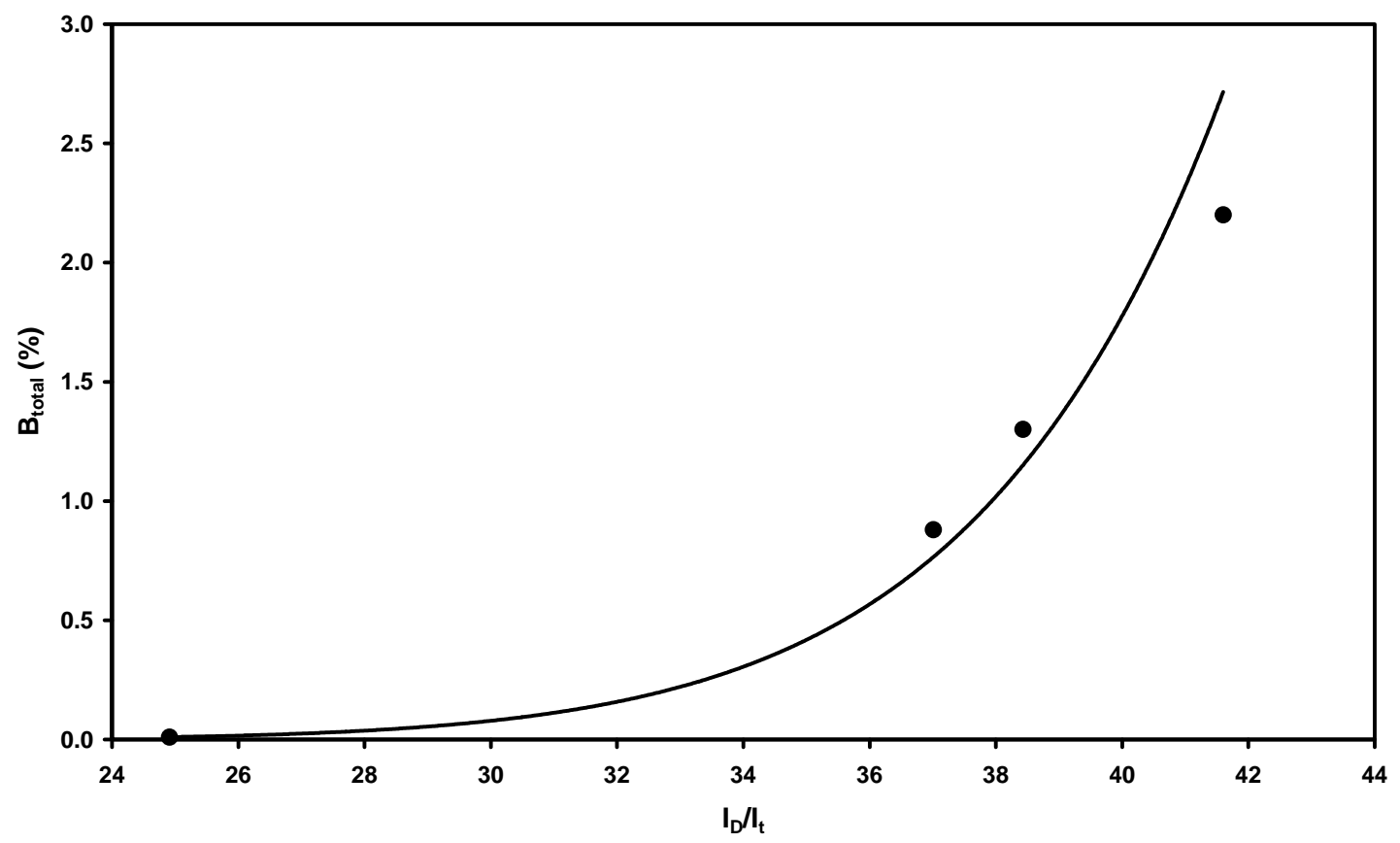

Fig. 9. Relationship between $\mathrm{I}_{\mathrm{D}} / \mathrm{I}_{\mathrm{t}}$ and the percentage of total boron (determined by ICPMS).

In the case of boron doped materials, it has been previously reported by Hagio et al. [44] and Wang et al. [45], that substitutional boron causes a distortion of the carbon atoms next to it, which reduces the symmetry of the structure and increases the intensity of the D-band. This effect is not present in the undoped foam and is more pronounced as the boron concentration increases. Fig. 9 refers to the $\%$ of total boron obtained by ICPMS. The same plot for the substitutional boron found in the XPS analysis is shown in 
Fig. 10, and displays a worse correlation, indicating that the presence of boron clusters might also produce a distorting effect on the graphitic layers.

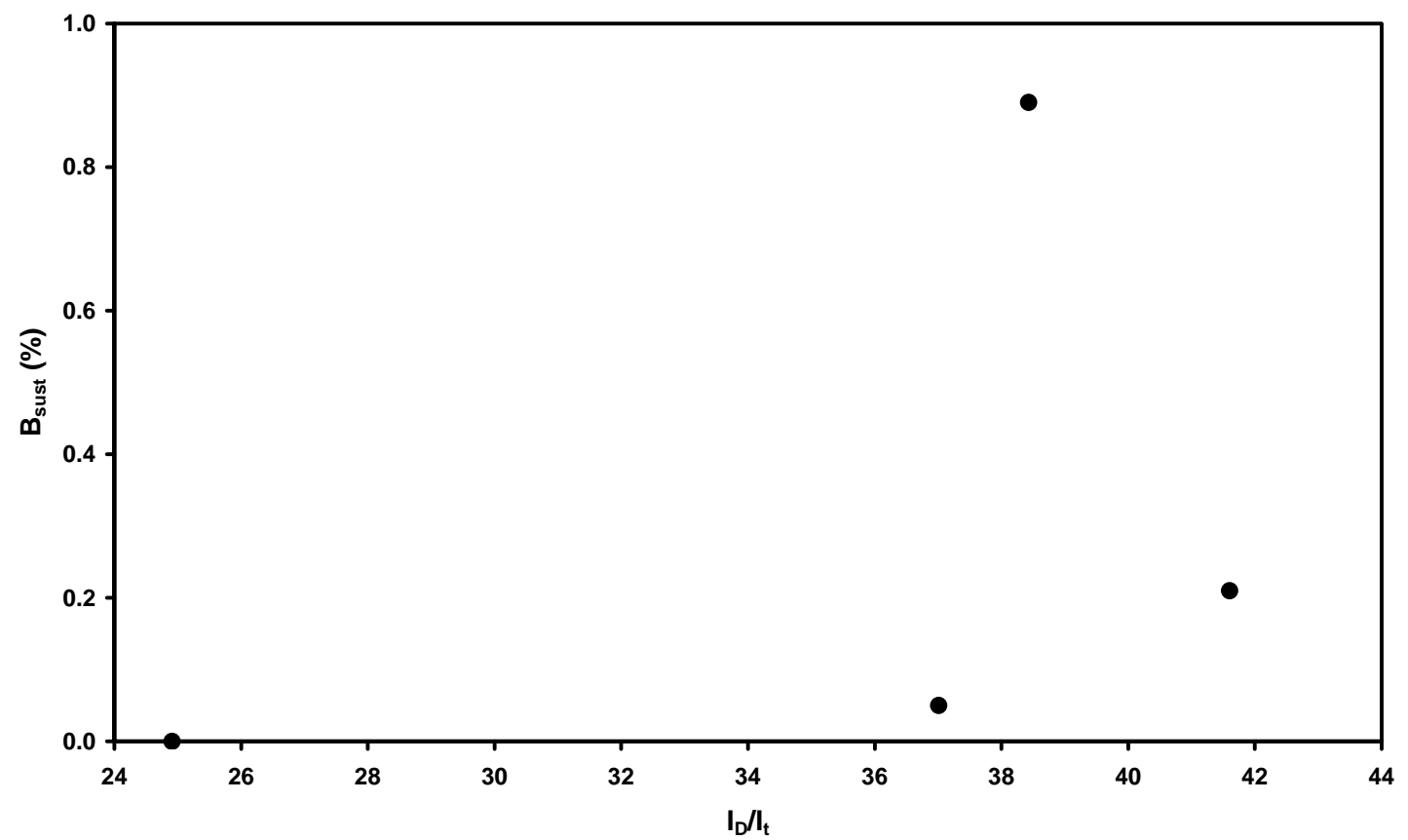

Fig. 10. Relationship between $\mathrm{I}_{\mathrm{D}} / \mathrm{I}_{\mathrm{t}}$ and the percentage of substitutional boron (determined by XPS).

\subsection{Oxidation behaviour}

Non-isothermal TG curves for the oxidation of doped and undoped graphitic foams have been obtained. The initial mass loss temperature and the residual mass determined from the TG curves are summarized in Table 8. The oxidation of foams $0.7 \mathrm{BC} 24$ and $1.5 \mathrm{BC} 24$ begins slightly below $700{ }^{\circ} \mathrm{C}$, whereas foam $0.0 \mathrm{~B} 24$ starts to oxidize at temperatures higher than $710^{\circ} \mathrm{C}$. Moreover, in foam $0.7 \mathrm{BO} 24$ total burn-off was achieved faster than in the rest. These observations indicate a catalytic oxidation effect at low B loadings in the foams doped with $\mathrm{B}_{4} \mathrm{C}$. 
Table 8

TGA results for the graphitic foams

\begin{tabular}{lcc}
\hline & Initial mass loss & Residual \\
Samples & temperature $\left({ }^{\circ} \mathrm{C}\right)$ & mass $(\%)$ \\
\hline $0.0 \mathrm{~B} 24$ & 709.7 & 0.0 \\
\hline $0.7 \mathrm{BO} 24$ & 732.1 & 1.8 \\
$1.5 \mathrm{BO} 24$ & 769.1 & 10.8 \\
$2.5 \mathrm{BO} 24$ & 781.2 & 27.0 \\
$5.0 \mathrm{BO} 24$ & 823.7 & 41.7 \\
\hline $0.7 \mathrm{BC} 24$ & 671.0 & 15.9 \\
$1.5 \mathrm{BC} 24$ & 648.2 & 18.8 \\
\hline $2.5 \mathrm{BC} 24$ & 796.1 & 28.8 \\
\hline $5.0 \mathrm{BC} 24$ & 822.3 & 50.0 \\
\hline $0.0 \mathrm{~PB} 24$ & 690.2 & 0.0 \\
\hline $1.9 \mathrm{~PB} 24$ & 702.7 & 4.4 \\
\hline 4.5PB24 & 788.3 & 28.6 \\
\hline & 838.8 & 59.2 \\
\hline
\end{tabular}

As the amount of boron added increases (Fig. 11), the oxidation-inhibiting effect starts to predominate, with temperatures at which oxidation starts reaching values above $800{ }^{\circ} \mathrm{C}$. Moreover, the doped foams have not yet been entirely oxidized at $1200{ }^{\circ} \mathrm{C}$ and the residues remaining in the crucible still retain the shape of the initial samples. The residual mass increases with the B loading (Fig. 12). 
Initial mass loss temperature vs. $B_{\exp }$

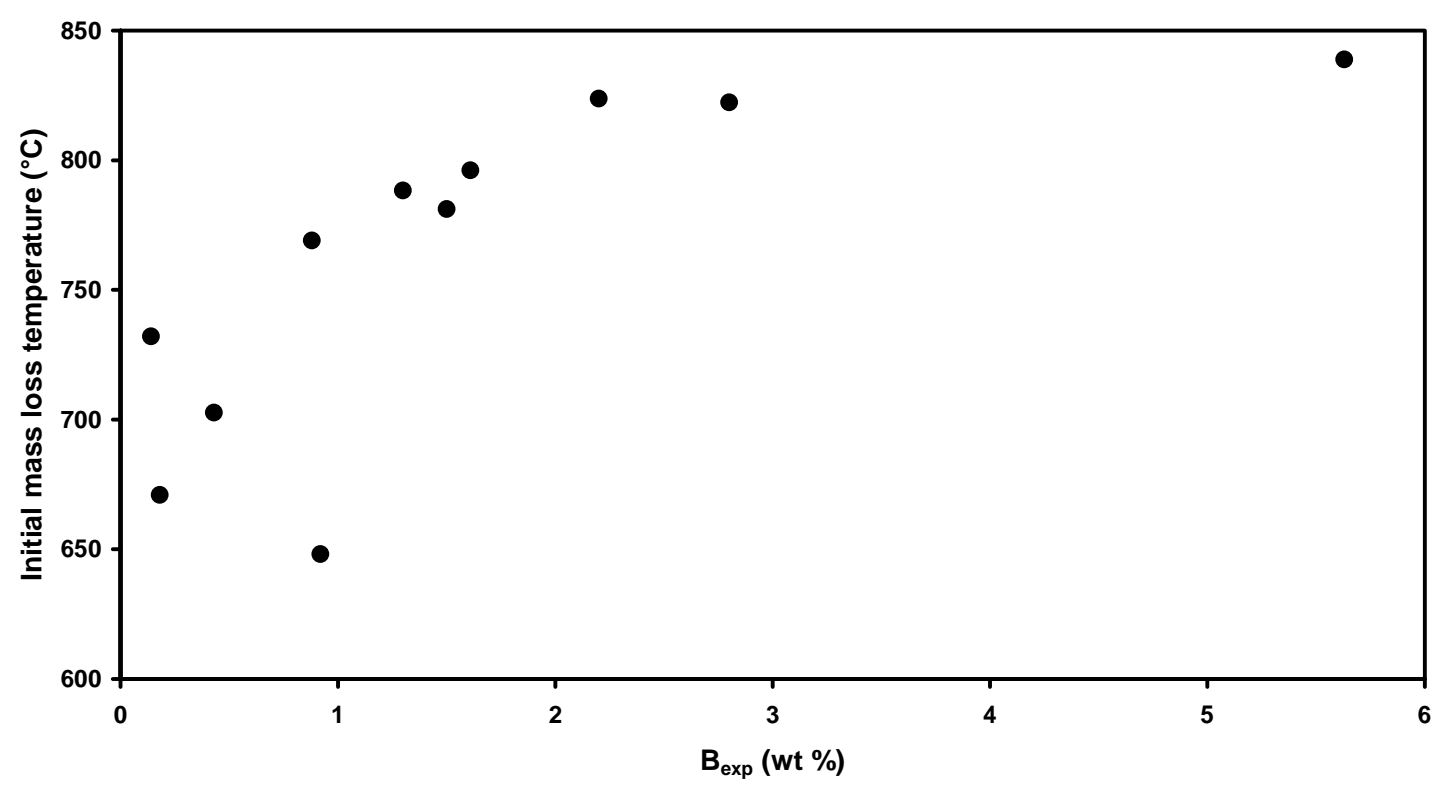

Fig. 11. Variation of the initial mass loss temperature in the TGA tests with the experimental B loading.

Residual mass vs. $B_{\exp }$

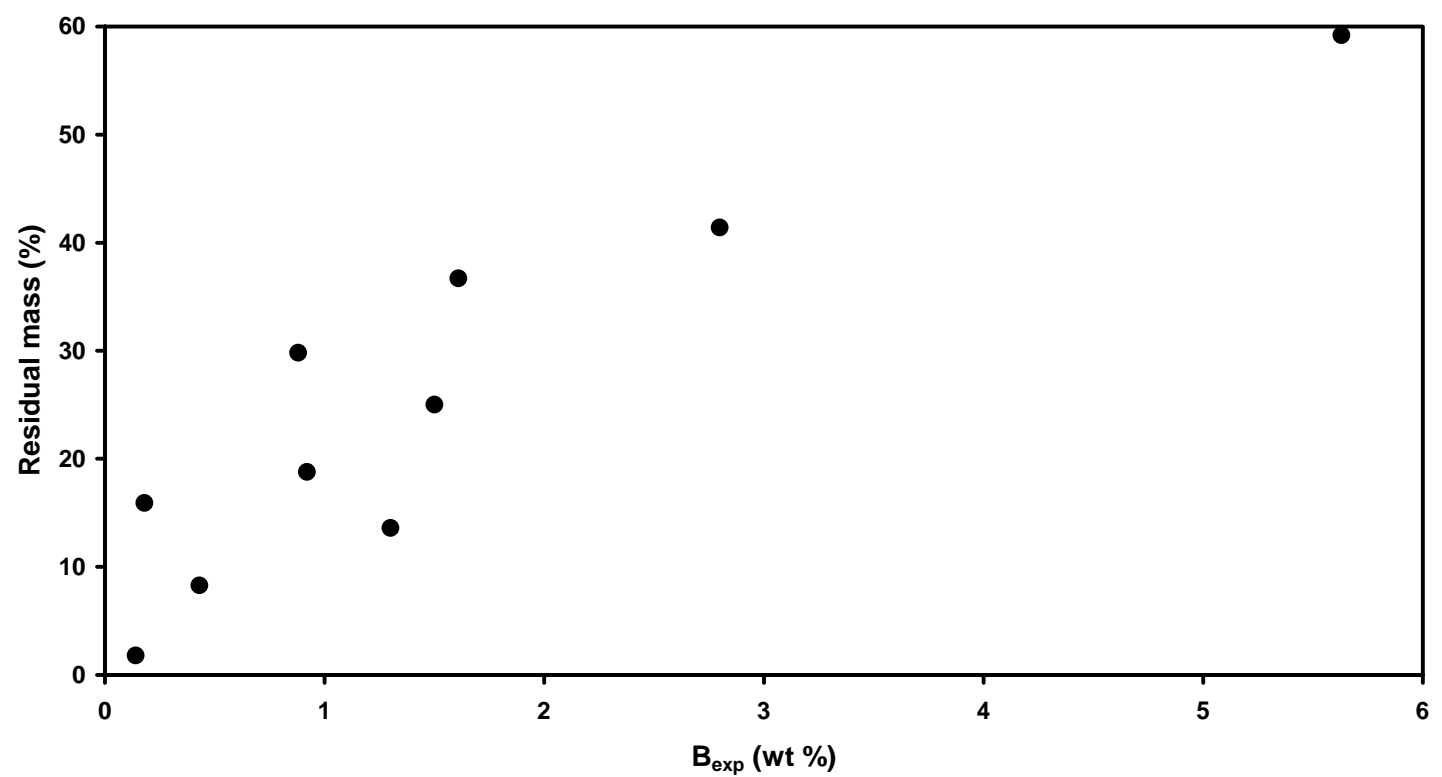

Fig. 12. Variation of the residual mass in the TGA tests with the experimental B loading. 


\section{Discussion}

The results obtained in this study confirm the existence of the two effects (inhibitory and catalytic) previously reported by other authors [29,32], in relation with the influence that the presence of boron exerts on the oxidation of carbon materials. Most of the graphitised boron-doped carbon foams display an enhanced resistance against oxidation, which is reflected in higher initial gasification temperatures and higher amounts of residual matter in the TGA experiments conducted under air. This finding is in good agreement with the improved graphitisation parameters obtained by the XRD analyses, which reveal a better degree of structural ordering. This is one of the causes reported as determinant in the oxidation inhibition produced by the presence of boron, which, together with the formation of a $\mathrm{B}_{2} \mathrm{O}_{3}$ layer, allegedly counteract the intrinsic oxidation catalytic effect of substitutional boron [32].

The only two exceptions to this general trend are two samples obtained by doping with low amounts of boron carbide $(0.7 \mathrm{BC} 24$ and $1.5 \mathrm{BC} 24)$, where the initial mass loss temperature starts below the value displayed by the reference sample, $0.0 \mathrm{~B} 24$ (Table 8). This catalytic effect observed when low concentrations of B are loaded was previously observed by Lee et al. [37], and was attributed to the graphite crystallites being of a much smaller size. In that study, only the effect of substitutional boron is taken into account, and its authors consider that the location of the boron atoms in the graphene layers is determinant. They postulate that the presence of large amounts of substitutional B close to the graphene edges rather than well inside the basal plane is the reason for the catalytic effect on the oxidation process. The affinity of oxygen for the reactive carbon sites is greater. High B loadings promote graphitisation and an increase 
in the size of crystallites, so that the possibility of finding substitutional B atoms next to the graphene edges is more remote. However, the graphitised samples that have a catalytic effect on oxidation in this study do not display the lowest crystallite sizes (Table 4).

Zhong et al. [32] reported that doped boron has a catalytic effect on the oxidation of carbon, when B is kept in low concentrations, and that several factors contribute to the inhibition of oxidation observed at higher B levels. Our results indicate that, clusters and $\mathrm{B}_{4} \mathrm{C}$ are the most abundant associations of $\mathrm{B}$, but, in spite of being low, the concentrations of substitutional B (B-C in Tables 6 and 7) are very influential in the graphitisation enhancement and consequently in the oxidation inhibition as B loading increases. Higher loadings of B, with an enhancement of the concentration of all forms, such as boron clusters, boron carbide and substitutional boron also originate the formation of a $\mathrm{B}_{2} \mathrm{O}_{3}$ shield upon oxidation, contributing to the inhibition of carbon oxidation.

\section{Conclusions}

Boron-loaded carbon foams can be prepared from coal and different boroncontaining precursors by using a controlled carbonisation process. A subsequent graphitisation process gives rise to foams with highly ordered graphitic structures. Boron promotes graphitisation with crystallite parameters approaching those of natural graphite in the foams with the highest B loadings. However, Raman spectroscopy revealed the presence of distortions in the graphitic layers, probably as a consequence of the presence of boron phases other than substitutional boron: B clusters, boron carbide and $\mathrm{BC}_{2} \mathrm{O}$ associations, as revealed by XPS and DRX. 
The presence of boron forms in the foams promotes two opposite effects on their oxidation behaviour. In The foams obtained employing low amounts of boron carbide, the presence of substitutional B results in a catalytic effect on the oxidation process. Hence, these foams display lower oxidation temperatures than the unloaded ones.

The other foams are more resistant to oxidation, as indicated by the higher temperatures and resultant residues. The enhanced structural order of the graphitic structures promoted by substitutional boron greatly contributes to oxidation resistance. The higher content of all $\mathrm{B}$ forms leading to the formation of a $\mathrm{B}_{2} \mathrm{O}_{3}$ layer under oxidation conditions is another factor responsible for this greater resistance of B-loaded graphitic foams.

\section{Aknowledgements}

The authors thank the Spanish Ministerio de Educación y Ciencia for financial support (Research Project MAT2005-04658).

\section{References}

[1] Gallego GC, Klett JW. Carbon foams for thermal management. Carbon 2003;41:1461-66.

[2] Druma AM, Alarm MK, Druma C. Analysis of thermal conduction in carbon foams. Int J Therm Sci 2004;43:1849-52. 
[3] Yang J, Xhen Z-M, Xue R-X. Study of mesophase pitch-based graphite foam used as anodic materials in lithium ion rechargeable batteries. J Materials Science 2005;40:1285-87.

[4] Beechem T, Lafdi K. Novel high strength graphitic foams. Carbon 2006;44:15481559

[5] Chen C, Kennel EB, Stiller AH, Stansberrry PG, Zondlo JW. Carbon foam derived from various precursors. Carbon 2006;44:1535-43.

[6] McMillan WJ. Light-weight porous carbon. US patent 3342555, 1967.

[7] Siripurapu S, Gay YJ, Royer JR, DeSimone JM, Spontak RJ, Khan SA. Generation of microcellular foams of PVDF and its blends using supercritical carbon dioxide in a continuous process. Polymer 2002;43:5511-20.

[8] Lei S, Guo Q, Shi J, Liu L. Preparation of phenolic-based carbon foam with controllable pore structure and high compressive strength. Carbon 2010;48:26446.

[9] Zhang S-p, Liu M-x, Gan L-h, Wu F-r, Xu Z-j, Hao Z-x et al. Synthesis of carbon foams with a high compressive strength from arylacetylene. New Carbon Materials 2010;25:9-14.

[10] Klett JW. Process for making carbon foam. US patent 6033506, 2000.

[11] Min G, Zengmin S, Weidong C, Hui L. Anisotropy of mesophase pitch-derived carbon foams. Carbon 2007;45:141-5.

[12] Calvo M, García R, Arenillas A, Suárez I, Moinelo SR. Carbon foams from coals. A preliminary study. Fuel 2005;41:2174-6.

[13] McKee DW. Oxidation protection of carbon materials. In: Thrower PA, editor. Chemistry and physics of carbon, vol 23, New York; Marcel Dekker; 1991, p. 173-232. 
[14] Fergus JW, Worrell WL. Silicon-carbide/boron-containing coatings for the oxidation protection of graphite. Carbon 1995;33:537-43.

[15] Isola C, Apendino P, Bosco F, Ferraris M, Salvo M. Protective glass coating for carbon-carbon composites. Carbon 1998;36:1213-8.

[16] Klett J, Lowden R, McMillan A. Oxidation protection of graphite foams. Proceedings, $2^{\text {nd }}$ International Carbon Conference. Lexington (Kentucky, USA): July 13-18, 2001.

[17] Marinkovic S. Substitutional solid solubility in carbon and graphite. In: Thrower PA, editor. Chemistry and physics of carbon, vol 19, New York; Marcel Dekker; 1984, p. 1-64.

[18] Allardice DJ, Walker Jr PL. The effect of substitutional boron on the kinetics of the carbon-oxygen reaction. Carbon 1970;8:375-85.

[19] Lowell CE. Solid solution of boron in graphite. J Am Ceram Soc 1967;50:142-4.

[20] Sogabe T, Matsuda T, Kuroda K, Hirohata Y, Hino T, Yamashina T. Preparation of $\mathrm{B}_{4} \mathrm{C}$-mixed graphite by pressureless sintering and its air oxidation behavior. Carbon 1995;33:1783-8.

[21] Rodriguez NM, Baker RTK. Fundamental studies of the influence of boron on the graphite-oxygen reaction using in situ electron microscopy techniques. J Mater Res 1993;8:1886-94.

[22] Jones LE, Thrower PA. The effect of boron on carbon fiber microstructure and reactivity. J Chim Phys 1987;84:1431-8.

[23] Jones LE, Thrower PA. Influence of boron on carbon fiber microstructure, physical properties, and oxidation behavior. Carbon 1991;29:251-69.

[24] Howe JY, Jones LE. Influence of boron on structure and oxidation behavior of graphite fiber. Carbon 2004;42:461-7. 
[25] Ragan S, Emmerson GT. The effect of heat-treatment temperature upon the properties of matrix-inhibited carbon-carbon composites. Carbon 1992;30:33944.

[26] Kowbel W, Huang Y, Tsou H. Effect of boron ion implantation on the oxidation behavior of three-dimensional carbon-carbon composite. Carbon 1993;31:355-63.

[27] Wu X, Radovic LR. Inhibition of catalytic oxidation of carbon/carbon composites by boron-doping. Carbon 2005;43:1768-77.

[28] Lee YJ, Joo HJ, Radovic LR. Preferential distribution and oxidation inhibiting/catalytic effects of boron in carbon fiber reinforced carbon (CFRC) composites. Carbon 2003;41:2591-600.

[29] Radovic LR, Karra M, Skokova K, Thrower PA. The role of substitutional boron in carbon oxidation. Carbon 1998;36:1841-54.

[30] Cermignani W, Paulson TE, Onneby C, Pantano CG. Synthesis and characterization of boron-doped carbons. Carbon 1995;33:367-74.

[31] Durkic T, Peric A, Lausevic M, Dekanski A, Neskovic O, Veljkovic M, et al. Boron and phosphorus doped glassy carbon: I. Surface properties. Carbon $1997 ; 35: 1567-72$

[32] Zhong DH, Sano H, Uchiyama Y, Kobayashi K. Effect of low level boron-doping on oxidation behavior of polyimide-derived carbon films. Carbon 2000;38:1199206.

[33] Lee YJ, Radovic LR. Oxidation inhibition effects of phosphorus and boron in different carbon fabrics. Carbon 2003;41:1987-97.

[34] Jacques S, Guette A, Bourrat X, Langlais F, Guimon C, Labrugere C. LPCVD and characterization of boron-containing pyrocarbon materials. Carbon 1996;34:113543. 
[35] Chesneau M, Beguin F, Conard J, Erre R, Thebault J. The antioxidation effect of boron oxide on a pyrocarbon. Carbon 1992;30:714-6.

[36] Eichner T, Braun M, Hüttinger KJ. Element-substitud polyaromatic mesophases: I. Boron-substitution with the pyridine-borane complex. Carbon 1996;34:1367-81.

[37] Lee Y-L, Uchiyama Y, Radovic LR. Effects of boron doping in low- and highsurface-area carbon powders. Carbon 2004;42:2233-44.

[38] Machnikowski J, Franckowiak E, Kierzek K, Waszak D, Benoit R, Béguin F. Lithium insertion into boron containing carbons prepared by co-pyrolysis of coaltar pitch and borane-pyridine complex. J Phys Chem of Solids 2004;65:153-8.

[39] Hamada T, Suzuki K, Kohno T, Sugiura T. Structure of coke powder heat-treated with boron. Carbon 2002;40:1203-10.

[40] Konno H, Nakahashi T, Inagaki M, Sogabe T. Nitrogen incorporation into boron doped graphite and formation of B-N bonding. Carbon 1999;37:471-5.

[41] Shirasaki T, Derré A, Menétrier M, Tressaud A, Flandrois S. Synthesis and characterization of boron-substitued carbons. Carbon 2000;38:1461-7.

[42] Tuinstra F, Koenig JL. Raman spectra of graphite. J Chem Phys 1970;53:1126-30.

[43] Cuesta A, Dhamelincourt P, Laureyns J, Martinez-Alonso A, Tascon JMD. Comparative performance of X-ray diffraction and Raman microprobe techniques for the study of carbon materials. J Mater Chem 1998;8:2875-9.

[44] Hagio T, Nakamizo M, Kobayashi K. Studies on X-Ray difraction and Raman spectra of B-doped natural graphite. Carbon 1989;27:259-263.

[45] Wang, Y, Alsmeyer, DC, McCreery, RL. Raman spectroscopy of carbon materials: structural basis of observed spectra. Chem Mater 1990;2:557-63. 